\title{
Evaluation of an educational programme for socially deprived asthma patients
}

\author{
M.A. de Oliveira, S.M. Faresin, V.F. Bruno, A.R. de Bittencourt, A.L.G. Fernandes
}

Evaluation of an educational programme for socially deprived asthma patients. M. Alenita de Oliveira, S.M. Faresin, V.F. Bruno, A.R. de Bittencourt, A.L.G. Fernandes. (C) ERS Journals Ltd 1999.

ABSTRACT: The aim of this study was to evaluate the effectiveness of an asthma education programme in moderate and severe asthma patients in a longitudinal, prospective and randomized study with a control group. Fifty-three asthmatic patients were studied, 26 of whom were assigned to the educational group and 27 to the control group.

The educational group attended the programme regularly for a period of 6 months. The programme included information about asthma, instruction on the appropriate use of medication and training in the metered dose inhaler (MDI) technique, and information about the identification and control of asthma attacks and the recognition of early signs of exacerbation. The control group was submitted to the routine care provided at the Asthma Clinic, with no formal instruction regarding asthma control. The groups were identical with regard to severity parameters, skills, lung function and quality of life at the beginning of the trial.

At the end of the study, the education group showed significant differences when compared with the control group (education/control (mean values)) with respect to: visits to the asthma emergency room over the previous 6 months, $0.7 / 2(p=0.03)$; nocturnal symptoms, $0.3 / 0.7(p=0.04)$; score of symptoms, $1.3 / 2(p=0.04)$. Improvements were also observed in skills and quality of life, knowledge of how to deal with attacks and how to control the environmental triggering factors, $73 / 35(<0.05)$; correct use of the MDI, 8/4 (0.001); understanding of the difference between relief and antiinflammatory medication, 86/20 $(<0.05)$; and in the global limitation quality of life score, $28 / 50(0.02)$.

It is concluded that the educational programme led to a significant improvement in asthma morbidity and that the implantation of educational programmes is possible for special populations when these programmes are adapted to the socioeconomic profile of the patients, with a significant gain in terms of the reduction of symptoms and improved pulmonary function and quality of life of asthmatics.

Eur Respir J 1999; 14: 908-914.

Asthma treatment has not led to impressive changes in morbidity and mortality, despite more knowledge about the inflammatory process involved in asthmatic airways, followed by the development of new drugs $[1,2]$. In many countries, an increase in the rate of emergency room (ER) visits and hospitalizations, as well as loss of school days and/or work days due to asthma, has shown the difficulty in providing adequate control of the disease. This is especially true when the studies are conducted on target populations with special characteristics such as poor and minority children in inner cities and socially deprived populations [3-6].

The International Consensus Report on Diagnosis and Management of Asthma (ICRDMA) [7] concluded in its guidelines that education is one of the critical components of asthma treatment. Few controlled randomized trials have been carried out to evaluate educational programmes in socially deprived asthmatic populations [8-11] and efforts to measure the value of education in terms of morbidity have been hampered by the lack of control groups.
Lung Division, Dept of Medicine, Federal University of São Paulo, São Paulo, Brazil

Correspondence: A.L.G. Fernandes

Disci-plina de Pneumologia

Rua Botucatu $7403^{\circ}$ andar

São Paulo S.P

CEP 04023-004

Brasil

Fax: 5511508 41268/2847301

Keywords: action plan asthma educational programme socially deprived population

Received: June 181999

Accepted after revision May 31999

This study was supported by the following scientific agencies: Conselho Nacional de Desenvolvimento Cientfico e Tecnológico $(\mathrm{CNPq})$ and Coordenação de Aperfeiçoamento de Pessoal de Ensino Superior (CAPES).

Presented in part at the International Meeting of the American Thoracic Society, Chicago, 1998.
MAYO et al. [8] performed a randomized trial involving a population with socioeconomic problems and demonstrated a reduction in hospital readmission rates and hospital day use rates. KeLSO et al. [9] reported a $41 \%$ reduction in ER visits by indigent minorities. The same investigator, studying African Americans in a nonrandomized control trial, reported significant reductions in the morbidity of asthma [10]. In New Zealand, D'SouzA et al. [11] introduced a credit-card self-management plan in a Maori community, with a significant reduction in the morbidity of asthma. However, this was a nonrandomized control trial.

Asthma is the fourth largest cause of hospital admission in Brazil (1996). It was reported to be the primary cause of hospitalization for patients aged 20-29 yrs, causing disability with great social and economic impact on the productive population [12]. The present study was designed as a randomized controlled trial to assess the effectiveness of population-based asthma management intervention and was especially tailored for deprived low-income populations of poor social and cultural backgrounds. This 
6 month educational programme has already been implemented in a deprived population with good results [13].

\section{Methods}

\section{Patients}

The study was conducted at the asthma outpatient clinic of the Lung Division, Federal University of São Paulo (UNIFESP-EPM)-Brazil, and was approved by the Human Investigation Ethical Committee of the Institution.

The patients were recruited from a computer database of asthma outpatients $(n=450)$. Eighty patients were selected and invited for an interview in which they were informed about the purpose of the study, as well as its duration and the chance to be placed in an educational or a control group; written consent was obtained. The patients who agreed to participate in the study were randomly assigned to one of these groups via the closed envelope technique.

A total of 53 patients with asthma confirmed by history and airflow, obstruction according to the criteria of the ICRDMA [7] were eligible to participate in the trial.

\section{Study design}

The patients were included in the trial and monitored at an outpatient clinic for 6 months; 26 of the patients were assigned to the educational group and 27 to the control group, in February-July 1996. All patients were submitted to the interview at the beginning and at the end of the study for assessment of the outcome measures.

Both groups were attended in the asthma outpatient department by the same team of physicians who were pneumologists in training under the supervision of University staff physicians.

Forms were provided by the physician for the patient to fill in, showing the frequency of diurnal and nocturnal asthma symptoms over the previous 3 weeks before the interview. Associated symptoms, exacerbations, current use of asthma medication, and physical examination data were recorded, and treatment was adjusted for each patient based on the ICRDMA [7] recommendations. These recommendations emphasize the reduction of symptombased therapy and the increased use of anti-inflammatory drugs to control underlying inflammation. Patients were taught to control mild to moderate symptoms with relief medication "as needed".

Both groups received a prescription for the medication indicated for their clinical presentation. The health department did not provide the drugs which had to be purchased by the patient. The professional team did not interfere with this but encouraged the patients to follow the prescribed treatment.

\section{The educational group}

The patients assigned to the educational group were divided into four subgroups and each subgroup was scheduled for a monthly visit over a period of 6 months.

On the occasion of the first visit, the investigators explained the difference between relief and anti-inflammatory medications on an individual basis. Simple diary cards were given to the patients, on which they had to tick "Yes" or "No" with respect to the occurrence of diurnal and nocturnal symptoms, thus improving their perception of asthma symptoms. When the patient was unable to fill out the diary card, someone in the family was requested to help them. At each follow-up visit the diary card was reviewed and discussed with the patient to stress the importance of management of the disease, and the treatment plan was readjusted according to the frequency of symptoms and the necessity of use of relief medication.

The use of the metered dose inhaler (MDI) was checked and the patient was retrained as necessary at each visit.

After consultation, a staff member of the asthma group explained the use of the prescribed drugs to each patient, sharing patient care responsibility and encouraging compliance with treatment.

Two $1 \mathrm{~h}$ sessions were scheduled after the third and fourth monthly visits, in which the patients in each subgroup received information about the concept of asthma and its management. The information covered signs and symptoms of exacerbation, triggering factors and environmental control, and some notions on relief (bronchodilator) and on preventive (anti-inflammatory) medication. A videotape produced by the investigators emphasized typical problems such as misconceptions about asthma, correct inhaler techniques and the introduction to a treatment plan based on the "abc" of asthma: a) identifying and reducing the factors that trigger asthma attacks, b) correct use of inhalers and spacers, and c) recognizing the warning signs of asthma episodes. The patients were encouraged to participate, to exchange information and to clarify their doubts about the disease. Reading material was distributed with information about asthma and diary cards were provided with the purpose of improving the perception of asthma symptoms during the daily routine.

Because the patients had problems in identifying their medication they were encouraged to bring their medications to the clinic visits where the difference between relief and prevention drugs was explained using visual aids (i.e. posters)

\section{Control group}

The control group followed the routine schedule of the Asthma Clinic, where their next follow-up appointment was determined by the attending physician according to individual patient needs. The number of visits for this group ranged 2-5 and the therapy was personalized for each patient based on the ICRDMA recommendations [7]. The patients did not receive formal instructions regarding asthma control nor did they fill out diary cards. They did not receive MDI training sessions or information about environmental control and early recognition of warning signs of asthma using posters, discussion sessions or video presentations. The control group only received instructions from the consulting physician. Regarding the use of medication and of the inhaler, they received only a verbal explanation.

\section{Outcome measures}

The outcomes of asthma severity, skills, lung function and quality of life were used to compare the educational study group with the control group and to determine the efficacy of the programme. 
Table 1. - Baseline characteristics of patients in the educational and control groups

\begin{tabular}{lcc}
\hline & $\begin{array}{c}\text { Educational } \\
\mathrm{n}=22\end{array}$ & $\begin{array}{c}\text { Control } \\
\mathrm{n}=20\end{array}$ \\
\hline Sex F/M & $20 / 2$ & $17 / 3$ \\
Age & $41 \pm 15$ & $38 \pm 17$ \\
Severe asthma \% & 36 & 35 \\
Moderate asthma \% & 64 & 65 \\
Comorbidity \% & 50 & 50 \\
FEV1\% pred. & $70 \pm 22$ & $80 \pm 19$ \\
Monthly family income in US\$ & $486 \pm 394$ & $413 \pm 233$ \\
Educational level & $5 \pm 4$ & $5 \pm 3$ \\
Illiterate \% & 9 & 10 \\
$<5$ yrs of education \% & 73 & 60 \\
$>5$ yrs of education \% & 18 & 30 \\
\hline
\end{tabular}

Data are presented as mean \pm SD unless otherwise indicated. F: female; M: male; FEV1: forced expiratory volume in one second.

\section{Asthma severity outcome}

Number of hospital admissions and emergency visits during the previous 6 months: patients were asked to report the number of hospitalizations and ER visits during the previous 6 months.

Nocturnal symptoms: frequency of nocturnal symptoms, based on how many times the patient experienced waking up too early or waking up during the night because of asthma symptoms over the previous 3 weeks before the interview.

Frequency of symptoms scale: the frequency of diurnal symptoms was scored using the following scale referring to the previous 3 weeks: $0=$ absence of symptoms; $1=$ symptoms present less than twice a week; $2=$ symptoms present more than twice a week; $3=$ daily symptoms.

\section{Skills}

Adequate use of the MDI: the use of the MDI was evaluated by a staff member using an eight step observational sequence scale recommended by MANZELLA et al. [14] to analyse the use of inhaled medication. The patients obtained a 10 when all steps were performed correctly, 5 when two steps were incorrectly performed, and 0 when more than two steps were performed incorrectly.

Avoidance of triggering factors and environmental control measures; the patients answered questions about prophylactic actions regarding their triggering factors and environmental challenges.

Difference between relief and prevention medication: the patients were tested about their knowledge concerning the recognition and use of drug medication. They were also tested to see if they knew whether their medication was used for relief or prevention.

\section{Lung function}

Peak expiratory flow rate (PEFR) pre- and postbronchodilator use: PEFR was measured before and after bronchodilator use during each follow-up visit. The Assess peak flow meter was used in accordance with standard techniques [7]. In each step the highest value obtained after three consecutive measurements was recorded and the percentage of predicted values was calculated based on the normogram of LEINER et al. [15].

\section{Quality of life questionnaire}

The asthma quality of life questionnaire based on JuNIPER et al. [16] and JoNES et al. [17] and adapted to the authors' local situation demonstrated a good correlation with severity of illness [18]. The questionnaire includes five main areas: 1) limitation of the patient's physical activities due to asthma symptoms; 2) frequency and severity of symptoms; 3 ) adherence to treatment; 4) socioeconomic limitation; and 5) psychosocial limitation. The questionnaire was applied during an interview because of the high incidence of illiteracy among these patients. Application of the questionnaire by the same investigator required $15-20 \mathrm{~min}$ both at the beginning and at the end of the 6 month programme.

The limitation of physical activity was evaluated by means of three series of questions. In two of these, the patient would choose five preferred activities which they routinely performed. The following scale was used, 1 =mild; $2=$ moderate; and $3=$ severe, with a maximum total score of 33 points. The frequency and severity of asthma symptoms were evaluated using two questions ( 3 points each) and the other areas were evaluated using standard concordance/discordance answers, with total agreement $=1$, total disagreement $=0$ and doubtful $=0.5$. The following maximum points were obtained: adherence (6 points), socioeconomic (11 points) and psychosocial (7 points).

The quality of life was calculated by the sum of the points scored by the patients in each item and the average in each area covered. The different points obtained in each area were balanced by expressing the total points as percentiles. The overall score was the percentile of total points obtained for the entire questionnaire. Lower scores indicated a better quality of life.

\section{Statistical analysis}

The outcomes for the evaluation of the efficacy of the programme were compared by the Wilcoxon test (for the same group) and the Mann-Whitney U-test (between groups) for quantitative variables such as number of hospital admissions, number of visits to the ER, sleep disturbances due to asthma, frequency of symptoms, quality of life score, score of MDI use, and PEFR. The McNemar, Fisher exact test or Chi-squared test was used for qualitative variables such as avoidance of triggering factors, environmental control measures, and understanding the difference between relief and prevention medication. Significance was defined as $\mathrm{p}<0.05$.

\section{Results}

Of the 53 patients initially enrolled in the study, 11 (21\%) were excluded because they did not complete the trial; 5 withdrew from the educational group and 6 from the control group. The analysis was then limited to 42 patients who completed the protocol.

Table 1 shows the main characteristics of the subjects included in the study. No significant differences were observed regarding clinical, functional or socioeconomic data between the educational and control groups. Overall, more females than males entered the study. 
Table 2. - Comparison of asthma severity, quality of life, and outcomes before the intervention between educational and control groups

\begin{tabular}{|c|c|c|c|}
\hline & $\begin{array}{l}\text { Educational } \\
\quad \mathrm{n}=22\end{array}$ & $\begin{array}{c}\text { Control } \\
n=20\end{array}$ & p-value \\
\hline \multicolumn{4}{|l|}{ Severity } \\
\hline Hospital admissions & $0.4 \pm 1$ & $0.7 \pm 1$ & 0.23 \\
\hline Emergency room visits & $4 \pm 5$ & $4 \pm 4$ & 0.52 \\
\hline 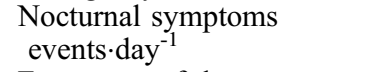 & $1 \pm 1.2$ & $1.4 \pm 1.2$ & 0.23 \\
\hline $\begin{array}{l}\text { Frequency of the symptoms } \\
\text { score }\end{array}$ & $2.5 \pm 0.7$ & $2.5 \pm 0.8$ & 0.79 \\
\hline \multicolumn{4}{|l|}{ Quality of life } \\
\hline $\begin{array}{l}\text { Quality of life questionnaire } \\
\text { score }\end{array}$ & $51 \pm 14$ & $58 \pm 12$ & 0.17 \\
\hline Physical limitation & $50 \pm 22$ & $56 \pm 14$ & 0.27 \\
\hline $\begin{array}{l}\text { Frequency and severity of } \\
\text { symptoms }\end{array}$ & $70 \pm 21$ & $80 \pm 17$ & 0.15 \\
\hline Treatment adherence & $35 \pm 21$ & $42 \pm 25$ & 0.31 \\
\hline Socioeconomic domain & $49 \pm 19$ & $59 \pm 18$ & 0.14 \\
\hline Psychosocial domain & $49 \pm 25$ & $53 \pm 26$ & 0.65 \\
\hline
\end{tabular}

Data are presented as mean \pm SD unless otherwise indicated. The p-values were calculated from Mann-Whitney U-tests.

The educational and control groups had similar severity parameters, skills, lung function and quality of life at baseline assessment (tables 2 and 3 ).

\section{Asthma severity}

None of the patients in the educational group were admitted to the hospital because of asthma exacerbation, While this was necessary for $30 \%$ of the patients in the control group (table 4). There was a borderline significance when the groups were compared by the MannWhitney U-test $(p=0.08)$. The number of ER visits decreased in both groups, but was significantly lower in the educational group $(\mathrm{p}=0.03)$. The same results were observed for nocturnal symptoms. Thirty per cent of

Table 3. - Comparisons of skills, knowledge and lung function outcomes before the intervention between the educational and control groups

\begin{tabular}{lccc}
\hline & $\begin{array}{c}\text { Educational } \\
\mathrm{n}=22\end{array}$ & $\begin{array}{c}\text { Control } \\
\mathrm{n}=20\end{array}$ & $\mathrm{p}$-value \\
\hline $\begin{array}{l}\text { Skills } \\
\text { Adequate use of } \\
\text { the MDI }\end{array}$ & $2 \pm 3$ & $3 \pm 4$ & $\mathrm{NS}$ \\
$\quad \begin{array}{l}\text { Patients with a score } \\
\text { of 10 }\end{array}$ & 4 & 15 & \\
$\quad \begin{array}{l}\text { Patients with a score } \\
\text { of 5 and 0 }\end{array}$ & 96 & 85 & \\
$\begin{array}{l}\text { Knowledge rescue/ } \\
\text { prevention medication }\end{array}$ & 18 & 25 & $\mathrm{NS}$ \\
$\begin{array}{l}\text { Triggers/environmental } \\
\text { control }\end{array}$ & 41 & 40 & $\mathrm{NS}$ \\
$\begin{array}{l}\text { Lung function } \\
\text { PEFR prebronchodilator } \\
\text { L.min }\end{array}$ & $264 \pm 90$ & $310 \pm 107$ & $\mathrm{NS}$ \\
$\begin{array}{l}\text { PEFR postbronchodilator } \\
\text { L.min }\end{array}$ & $345 \pm 87$ & $388 \pm 103$ & $\mathrm{NS}$ \\
\hline
\end{tabular}

Data are presented as mean \pm SD or as percentages. MDI: metered dose inhaler; PEFR: peak expiratory flow rate; NS: nonsignificant. control patients woke up at least twice during the night while this was true for only $9 \%$ of the patients in the educational group.

The diurnal symptoms according to frequency of the symptom scale were significantly-lower in the educational group than in the control group $(\mathrm{p}=0.04)$. Seventy per cent of the control group had diurnal symptoms scores of 2 and 3 , while only $36 \%$ of the educational group had the same scores.

\section{Skills and knowledge}

No differences were found in the proportion of patients with a score of 10 in either group before intervention. However, the patients from the educational group showed significant improvement in the correct use of the MDI $(\mathrm{p}<0.001)$. After the intervention, the proportion of patients with a score of 10 increased from $4 \%$ to $77 \%$ in the educational group, while no improvement was observed in the control group (table 5).

Seventy-three per cent of the patients in the educational group correctly answered questions about prophylactic actions regarding their triggering factors and environmental challenges, as opposed to only $35 \%$ of the control patients $(p<0.05)$. Eighty-six per cent of the patients in the educational group were able to recognise their medications and knew whether they were taken for relief or prevention, as opposed to only $20 \%$ of the control patients $(\mathrm{p}<0.05)$ (table 5).

\section{Lung function}

After intervention, the patients in the educational group showed significant improvement in prebronchodilator PEFR (from $264 \mathrm{~L} \cdot \mathrm{min}^{-1}$ to $367 \mathrm{~L} \cdot \mathrm{min}^{-1}(\mathrm{p}=0.003)$ and in postbronchodilator PEFR from $345 \mathrm{~L} \cdot \mathrm{min}^{-1}$ to 401 $\mathrm{L} \cdot \mathrm{min}^{-1}(\mathrm{p}=0.008)$ while the patients in the control group showed no change in prebronchodilator PEFR before = $310 \mathrm{~L} \cdot \mathrm{min}^{-1}$, after $\left.=323 \mathrm{~L} \cdot \mathrm{min}^{-1},(p=\mathrm{NS})\right)$ or postbronchodilator PEFR (before $=388 \mathrm{~L} \cdot \mathrm{min}^{-1}$ after $=401 \mathrm{~L} \cdot \mathrm{min}^{-1}$, $(\mathrm{p}=\mathrm{NS})$ ). However, no significant differences in PEFR were observed between groups at the final evaluation (table 5).

\section{Quality of life}

After the intervention, both groups showed a significant improvement in overall quality of life. However, comparison of the groups at the end of the study showed better scores for the quality of life of the educational group $(\mathrm{p}=0.0005)$. (table 4).

\section{Drug therapy}

Table 6 shows the percentage of medication used by the patients in both groups before and after the programme. There was no significant difference in the percentage of patients who used continuous oral steroids before and after the programme. Three patients with moderate asthma in the educational group and 1 patient in the control group had been using self-medication with oral steroids. The use of inhaled corticosteroids increased significantly among the patients in the educational group, but remained unchanged among the patients in the control group. 
Table 4. - Comparison of asthma severity, quality of life outcomes after the intervention between educational and control groups

\begin{tabular}{|c|c|c|c|}
\hline & $\begin{array}{l}\text { Educational } \\
\quad \mathrm{n}=22\end{array}$ & $\begin{array}{c}\text { Control } \\
n=20\end{array}$ & p-value \\
\hline \multicolumn{4}{|l|}{ Severity } \\
\hline Hospital admissions & 0 & $0.5 \pm 0.8$ & 0.08 \\
\hline Emergency room visits & $0.7 \pm 1.0$ & $2 \pm 2$ & 0.03 \\
\hline 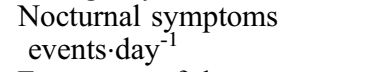 & $0.3 \pm 0.5$ & $0.7 \pm 1$ & 0.04 \\
\hline $\begin{array}{l}\text { Frequency of the symptoms } \\
\text { score } \\
\text { Quality of life }\end{array}$ & $1.3 \pm 1$ & $2 \pm 1$ & 0.04 \\
\hline $\begin{array}{l}\text { Quality of life questionnaire } \\
\text { score }\end{array}$ & $28 \pm 17$ & $50 \pm 15$ & 0.0005 \\
\hline Physical limitation & $26 \pm 23$ & $51 \pm 19$ & 0.002 \\
\hline $\begin{array}{l}\text { Frequency and severity of } \\
\text { symptoms }\end{array}$ & $37 \pm 32$ & $69 \pm 25$ & 0.002 \\
\hline Treatment adherence & $13 \pm 17$ & $34 \pm 25$ & 0.007 \\
\hline Socioeconomic domain & $33 \pm 21$ & $53 \pm 20$ & 0.004 \\
\hline Psychosocial domain & $32 \pm 18$ & $49 \pm 24$ & 0.01 \\
\hline
\end{tabular}

Data are presented as mean \pm SD unless otherwise indicated. The p-values were calculated from Mann-Whitney U-tests.

\section{Discussion}

The programme, which was specially tailored for the deprived socioeconomic situation of the target Brazilian population, consisted of maximum optimization in health care attendance and educational instructions.

The results confirmed previous findings that educational programmes are feasible for the authors' population and cause a decrease in morbidity parameters, with improved management of asthma [13]. In order to evaluate the effectiveness of this educational programme, the authors' included in the study patients with learning disabilities and comorbidity seen at the University Hospital Centre. It was decided not to test the ability of the patient to follow a prescription as an inclusion criterion since this might

Table 5. - Comparisons of skills, knowledge and lung function outcomes after the intervention between the educational and control groups

\begin{tabular}{lccc}
\hline & $\begin{array}{c}\text { Educational } \\
\mathrm{n}=22\end{array}$ & $\begin{array}{c}\text { Control } \\
\mathrm{n}=20\end{array}$ & $\mathrm{p}$-value \\
\hline $\begin{array}{l}\text { Skills } \\
\text { Adequate use of } \\
\text { the MDI }\end{array}$ & $8 \pm 3$ & $4 \pm 4$ & $0.001^{*}$ \\
$\begin{array}{l}\text { Patients with a score } \\
\text { of 10 }\end{array}$ & 77 & 25 & \\
$\quad \begin{array}{l}\text { Patients with a score } \\
\text { of 5 and 0 }\end{array}$ & 23 & 75 & \\
$\begin{array}{l}\text { Knowledge rescue/ } \\
\text { prevention medication }\end{array}$ & 86 & 20 & $<0.05^{\dagger}$ \\
$\begin{array}{l}\text { Triggers/environmental } \\
\text { control }\end{array}$ & 73 & 35 & $<0.05^{\dagger}$ \\
$\begin{array}{l}\text { Lung function } \\
\text { PEFR prebronchodilator }\end{array}$ & $367 \pm 137$ & $323 \pm 100$ & $0.3^{*}$ \\
$\begin{array}{l}\text { L.min } \\
\text { PEFR postbronchodilator } \\
\text { L·min }\end{array}$ & $401 \pm 114$ & $401 \pm 119$ & $0.5^{*}$ \\
\hline
\end{tabular}

Data are presented as mean \pm SD or as percentagess. *: MannWhitney U-test; ${ }^{\dagger}:$ Fisher's exact or Chi-squared test. MDI: metered dose inhaler; PEFR: peak expiratory flow rate. have excluded the patients more likely to be unresponsive to the proposed treatment. The high number of unemployed or part-time workers did not allow the estimation of the real socioeconomic impact of the disease on the study population.

Attendants were predominantly females showing the same distribution as observed in the authors' Asthma Clinic [19]. However, other reports have also shown similar rates of female participants, ranging $60-76 \%[6,20,21]$. It is not known whether this indicates more severe disease among females or whether it is a result of females seeking medical attention more frequently than males.

Initially, a high rate of ER visits, hospital admissions, and high symptom scores that reflected poor disease control and a more limited lifestyle of the patients compared to results from other studies was observed [22]. This may be further attributed to the reference status of the hospital, which treats a larger proportion of patients with severe asthma. Also, the severity of asthma may have been the result of socioeconomic, educational and psychological background, factors that have been shown to increase asthma morbidity $[3,23]$.

Patients were not provided with drugs because the investigators wanted to simulate the situation in their public health care system, which does not provide all medications free of charge (inhaled steroids are rarely available). One of the purposes of the study was to reinforce and highlight the importance of each patient providing their own medication. Interestingly, $95 \%$ of the patients in the educational group were taking inhaled steroids after the intervention, a fact that was not observed in the control group, treated by the same medical team.

The impact of this asthma educational programme on the morbidity of the study population was evident in terms of most severity parameters. There was a decrease in hospital admissions in the educational group, but due to the small number of patients studied, this did not reach statistical significance

When previous studies directed at socially deprived populations were analysed, the current authors observed a significant impact on morbidity, as described by MAYO et al. [8]. These investigators demonstrated a reduction in hospital readmission rates and hospital day use rates. However, in their study the preventive medication was supplied by the pharmacy, whereas in the current study the asthmatic subjects paid for their own medication. MAYO et al. [8] questioned the results of the programme. If they had not supplied the medication to the patients, would the results have been different? The current results showed that interaction between the medical care provider and the patients resulted in compliance with treatment. The preventive medications were not available at the pharmacy and the patients in the educational group continued to use the appropriate medication whereas the control group did not.

In a programme that emphasized the use of inhaled corticosteroids combined with patient education, KELSO et al. [10] also showed reduction in the ER visits and hospitalizations.

Other controlled randomized clinical trials [24, 25] using self-management plans have shown improved outcomes in asthma morbidity but their target populations were not comparable to the current population. LAHDENSUO et al. [24] studied patients with mild and moderately severe 
Table 6. - Medication used by patients in the educational and control groups

\begin{tabular}{lccccccc}
\hline & \multicolumn{3}{c}{ Educational } & & \multicolumn{3}{c}{ Control } \\
\cline { 2 - 4 } \cline { 6 - 8 } & Before & After & p-value & & Before & After & p-value \\
\hline Oral corticosteroids & 55 & 50 & 0.67 & & 35 & 40 & 0.50 \\
Inhaled corticosteroids & 41 & 95 & 0.0002 & & 50 & 50 & 0.65 \\
Methylxanthines & 36 & 41 & 0.50 & & 30 & 45 & 0.22 \\
Oral $\beta_{2}$-agonists & 14 & 0 & 0.12 & & 20 & 15 & 0.50 \\
Inhaled $\beta_{2}$-agonists & 86 & 100 & 0.12 & & 85 & 85 & 0.68 \\
Inhaled long-acting $\beta_{2}$-agonists & 5 & 5 & NA & 0 & 0 & NA \\
\hline
\end{tabular}

Data are presented as percentages. The p-values were calculated from the McNemar test. NA: not applicable.

asthma but did not determine their socioeconomic level. In Spain, Ignácio-Garcia and GonZales-Santos [25] studied patients of a higher socioeconomic level than the current population.

In populations of a high socioeconomic level the implementation of the educational programme led to improvement of patient information about asthma but did not demonstrate a decrease in morbidity $[22,26]$. These results may indicate that patients with favourable socioeconomic status and/or adequate prescriptions would not necessarily need rigorous standardized educational programmes, except in high risk groups, since the routine approach offers the information necessary for good asthma control.

The reduction of morbidity may be due to a variety of factors such as acquisition of knowledge, compliance with treatment, adequacy of medical treatment, and especially receiving more attention from the medical team. It is not possible to determine from this study whether specific features of the programme led to the reduction in asthma morbidity. Undoubtedly the increased use of regularly inhaled corticosteroids was the main cause of the improvement in asthma morbidity in the educational group. In addition, reduction of morbidity was due to the development of good patient-doctor relationships leading to better education.

In the educational group, patients showed a significant improvement in knowledge about management of asthma disease. Proper use of the inhaler and an appropriate treatment schedule are important for achieving full benefit from the medications. A significant increase in pre- and postbronchodilator PEFR was observed in the educational group but not in the control group. This effect on lung function may possibly be explained by the change in drug therapy that occurred in the intervention group.

In regard to quality of life, this improvement was more pronounced in terms of limitation of physical activities and frequency of symptoms, which was expected since these reflect better control of the disease. The authors preferred to use a questionnaire applied in the form of an interview because many of the patients had difficulties in filling out self-administered questionnaires. The most important validation of the questionnaire is a good association between the score obtained and the severity of clinical asthma expression. In a previous report the authors have shown a good correlation between the overall score obtained with the questionnaire and the severity of illness, PEFR and bronchial reversibility [18].

A brief comment is appropriate in regard to the measurements. The authors did not require the patients to fill out a complex diary card because most of them were unable to do it without intensive training. The simple diary card helped the patients to improve their perception of asthma symptoms. In the study population, the presence of asthma symptoms is often interpreted as normal, a fact which has also been observed in other studies on low income patients [27]. The main objective of the research was to evaluate the effectiveness of an educational programme specially designed for this population, taking into consideration the unique characteristics of the patients such as illiteracy, difficulties in taking prescribed medication and comorbidity.

Although the characteristics of the population were not favourable for asthma education [28], a reduction in the number of visits to the emergency room and in the symptom scores, improvement of knowledge and quality of life, and changes in medication compliance were all observed. These findings support the theory that educational programmes aimed at low-income populations should be encouraged and developed to reduce asthma morbidity. It is believed that educational asthma programmes should be implemented in order to more effectively assist patients in the reduction of morbidity. These programmes should also involve recycling and updating on the part of the physicians, the improvement of asthma management, and the allocation of increased health care resources in order to reduce direct and indirect cost.

\footnotetext{
Acknowledgements. The authors thank J. Wright and E. Greene for their collaboration in the preparation of the manuscript.
}

\section{References}

1. Dahlén S-E. Inflammation in asthma: what are the mechanisms? Eur Respir Rev 1996; 6: 32: 11-14.

2. Weitzman M, Gortmaker SL, Sobol AM, Perrin JM. Recent trends in the prevalence and severity of childhood asthma. JAMA 1992; 268: 2673-2677.

3. Rea HH, Scragg R, Jackson R, Beajlehole R, Fenwick J, Sutherland DC. A case-control study of deaths from asthma. Thorax 1986; 41(11): 833-839.

4. Kattan M, Mitchell H, Eggleston P, et al. Characteristics of inner-city children with asthma: The National Cooperative Inner-City Asthma Study. Pediatric Pulmonology 1997; 24: 253-262.

5. Birkhead G, Attaway NJ, Strunk RC, Townsend MC, Teutsch S. Investigation of a cluster of deaths of adolescents from asthma: evidence implicating inadequate treatment and poor patient adherence with medications. $J$ Allergy Clin Immunol 1989; 84: 484-491. 
6. Hartert TV, Windom HH, Peebles RS Jr, Freidhoff LR, Togias A. Inadequate outpatient medical therapy for patients with asthma admitted to two urban hospitals. $\mathrm{Am}$ J Med 1996; 100: 386-394.

7. Anonymous. Global initiative for asthma. National Heart, Lung, and Blood Institute, Bethesda, MD, USA, 1995, 953659 .

8. Mayo PH, Richman J, Harris HW. Results of a program to reduce admissions for adult asthma. Ann Intern Med 1990; 112: 864-871.

9. Kelso TM, Self TH, Rumbak MJ, Stephens MA, Garret W, Arheart KL. Educational and long term therapeutic intervention in the emergency department effect on outcomes in adult indigent minority asthmatics. Am J Emerg Med 1995; 13: 632-637.

10. Kelso TM, Abou-Shala N, Heilker GM, Arheart KL, Portner TS, Self TH. Comprehensive long-term management program for asthma: effect on outcomes in adult African-Americans. Am J Med Sci 1996; 311: 272-280.

11. D'Souza W, Crane J, Burgess C, et al. Community-based asthma care: trial of a "credit card" asthma selfmanagement plan. Eur Respir J 1994; 7: 1260-1265.

12. AnonymousDatabase of Brazilian Government Health System (SIH-SUS), report 1996. http://www.datasus. gov.br

13. De Oliveira MA, Bruno VE, Ballini L, Jardim JRB, Fernandes ALG. Evaluation of an educational program for the asthma control in adults. J of Asthma 1997; 34: 395-403.

14. Manzella BA, Brooks CM, Richards JM, Windsor RN, Soong S, Bailey WC. Assessing the use of metered dose inhalers by adults with asthma. $J$ of Asthma 1989; 26 : 223-230.

15. Leiner CG, Abramowtiz S, Small MJ, Stemby VB, Lewis WA. Expiratory peak flow rate. Standard values for normal subjects. Use as a clinical test of ventilatory function. Am Rev Respir Dis 1963; 88: 644-651.

16. Juniper EF, Guyatt GH, Epstein RS, Ferrie PJ, Jaeschke R, Hiller TK. Evaluation of impairment of health related quality of life in asthma, development of a questionnaire for use in clinical trial. Thorax 1992; 47: 76-83.

17. Jones PW, Quirk FH, Baveystock CM, Littlejohns P. A self-complete measure of health status for chronic airflow limitation - The St- George's Respiratory Questionnaire. Am Rev Respir Dis 1992; 145: 1321-1327.

18. Fernandes ALG, Oliveira MA, Glachan R. Evaluation of impairment of health related quality of life in asthma severity in adult asthmatic patients [abstract]. Am Respir Crit Care Med 1995; 151 (Suppl. 4): A592.

19. Oliveira MA, Gindro E, Yamashiro SN, Glanchan QR, Fernandes ALG. Caracterśticas epidemiológicas e clńicas de pacientes portadores de asma brônquica. Jornal de Pneumologia 1994; 20: 4.

20. Bailey WC, Richards JM Jr, Brooks CM, Soong SJ, Windsor RA, Manzella BA. A randomized trial to improve self-management practices of adults with asthma. Arch Intern Med 1990; 150: 1664-1668.

21. Yoon R, McKenzie DK, Bauman A, Miles DA. Controlled trial evaluation of an asthma education programme for adults Thorax 1993; 48: 1110-1116.

22. Allen RM, Jones MP, Oldenburg B. Randomised trial of an asthma self-management program for adults. Thorax 1995; 50: 731-738.

23. Boulet LP, Deschesnes F, Turcotte H, Gignac F. Near-fatal asthma clinical and physiologic features, perception of bronchoconstriction and psychologic profile. $J$ Allergy Clin Immunol 1991; 88: 838-846.

24. Lahdensuo A, Haahtela T, Herrala J, et al. Randomised comparison of guided self-management and traditional treatment of asthma over one year. Br Med J 1996; 312: 748-752.

25. lgnácio-Garcia JM, Gonzales-Santos P. Asthma selfmanagement education program by home monitoring of peak expiratory flow. Am J Respir Crit Care Med 1995; 151: 353-359.

26. Coté J, Cartier A, Robichaud P, et al. Influence on asthma morbidity of asthma education programs based on selfmanagement plans following treatment optimization. $\mathrm{Am}$ J Respir Crit Care Med 1997; 155: 1509-1514.

27. Lewis MA, de la Sota A, Rachelefsky G, Lewis CE, Quinones H, Richards W. ACT-Asthma control y tratamiento para niños: a progress report. Health Educ $Q$ 1987; 14: 281-290.

28. FitzGerald JM. Psychosocial barriers to asthma education. Chest 1994; 106 (4 Suppl): 260S-263S. 